\title{
ОСОБЕННОСТИ \\ ПРЕПОДАВАНИЯ АНАТОМИИ И ФИЗИОЛОГИИ ЧЕЛОВЕКА ДЛЯ СТУДЕНТОВ, ОБУЧАЮЩИХСЯ ПО НАПРАВЛЕНИЮ «ФИЗИЧЕСКАЯ КУЛЬТУРА»
}

\section{Погонышева И.А., Скоробогатова О.Н.}

В статье рассмотрены особенности преподавания анатомии и физиологии человека студентам, обучающимся по направлению «физическая культура». Преподавание анатомии и физиологии человека для будущих специалистов физической культуры и спорта имеет свои особенности, по сравнению с таковым для студентов медицинских вузов и биологических факультетов университетов. Рассматриваются традиционные и инновационные методы обучения в рамках дисииплин анатомия и физиология человека.

Ключевые слова: особенности преподавания; анатомия человека; физиология человека; технологии обучения.

\section{FEATURES OF TEACHING HUMAN ANATOMY AND PHYSIOLOGY FOR STUDENTS WHO ARE TRAINING IN THE DIRECTION "PHYSICAL CULTURE"}

\section{Pogonysheva I.A., Skorobogatova O.N.}

Features of teaching human anatomy and physiology to students who are studying in the direction of "physical culture" are considered in the article. Teaching human anatomy and physiology at medical universities and biological departments of universities is different from teaching students who are going to engage in physical education and sports. Traditional and innovative teaching methods are considered within the disciplines of human anatomy and physiology.

Keywords: teaching features; human anatomy; human physiology; teaching technologies. 
Дисциплины медико-биологического цикла занимают значимое место в системе высшего образования не только в обучении студентов медицинских вузов и биологических факультетов. Особую важность приобретает знание анатомии и физиологии бакалаврами, обучающимися по направлению «Физическая культура». Преподавание таких дисциплин как анатомия и физиология человека студентам разных факультетов предполагает учет специфических особенностей обучения $[5,9]$. Будущие специалисты в области физкультуры и спорта должны обучаться медико-биологическим дисциплинам с учетом профессиональных стандартов. Специфика профессиональной деятельности специалиста по физической культуре и спорту требует глубокого понимания морфофункциональных особенностей организма человека, поэтому усиление в образовательной программе подготовки бакалавров по физической культуре педагогической составляющей не должно идти в ущерб формированию анатомо-физиологических и здоровьесберегающих компетенций выпускников $[2,7,10]$.

Анатомия человека и физиология человека являются значимыми медико-биологическими дисциплинами, которые входят в основную образовательную программу (ОП) подготовки бакалавров по направлению 49.03.01 «Физическая культура». Они составляют теоретико-методологическую основу для других курсов, которые студенты изучают в последующих семестрах: физиологии физической культуры и спорта, спортивной медицины, мониторинга физического состояния организма, биохимии, ЛФК и основы массажа и др.

Изучение этих дисциплин дает основу для понимания и научного обоснования сомато-физиологических изменений организма человека, которые происходят в процессе адаптации к регулярным физическим нагрузкам. Недостаток знаний учителя физической культуры, тренера, или инструктора по фитнесу, касающихся морфофункциональных особенностей органов и систем человека может привести к негативным последствиям для здоровья их подопечных во время учебно-тренировочного процесса.

Преподавание анатомии и физиологии человека для будущих специалистов физической культуры и спорта имеет свои особенности, 
по сравнению с таковым для студентов медицинских вузов и биологических факультетов университетов. Отличия не только в меньшем количестве часов, выделяемых на практические, лекционные занятия и самостоятельную работу, но и в наглядном обеспечении, в отсутствии фиксированных влажных анатомических препаратов, трупного материала, которые не используются на факультетах физической культуры и спорта. Короткие сроки обучения, большие объемы информации и высокие требования к знаниям, умениям и навыкам студентов заставляют совершенствовать образовательные технологии, разрабатывать и внедрять новые формы представление учебного материала.

Важность преподавания дисциплин медико-биологического цикла отражено в основной образовательной программе: дисциплины «Анатомия человека» и «Физиология человека» входят в базовую часть ОП направления подготовки 49.03.01 «Физическая культура», уровень образования - бакалавриат. Вариативная часть учебного плана дополнена и другими медико-биологическими дисциплинами: «Физиология физического воспитания и спорта» и «Спортивная медицина». Анатомию и физиологию человека бакалавры факультета физической культуры и спорта Нижневартовского государственного университета изучают на первом курсе. Наличие базовых и вариативных дисциплин позволяет обращаться к анатомо-физиологическим знаниям, умениям и навыкам чаще, что стимулирует запоминание материала студентами [6].

Знания будут эффективнее усваиваться в том случае, если они представляют для студентов практический интерес. Поэтому в ходе преподавания анатомии и физиологии акцентируется внимание на морфофункциональных изменениях органов и систем спортсмена под воздействием физической нагрузки. На практических занятиях студенты получают навыки определения и оценки основных соматофизиологических параметров систем организма: сердечнососудистой, дыхательной, нервной, опорно-двигательной. Актуальным является также освоение студентами психофизиологических тестов, умение интерпретировать полученные результаты, что позволит в 
дальнейшем выпускникам активно использовать полученные навыки в ходе самостоятельной деятельности, работы в качестве учителя физической культуры или тренера по определенному виду спорта [1].

Анатомия и физиология считаются одними из самых сложных по уровню освоения курсов. В сложившейся ситуации на помощь преподавателю приходят инновационные технологии, которые можно с успехом использовать при изучении данных дисциплин $[3,7$, $8,11]$. Усовершенствование и оптимизация существующих традиционных методик обучения и использование новых информационных технологий - это направление, которое позволит студентам, обучающимся по направлению «Физическая культура», усваивать строение или функционирование отдельной системы организма человека за одно академическое занятие и закреплять эти знания в ходе лабораторной работы.

Наряду с традиционными классическими методами изучения организма человека, такими как применение световой микроскопии, антропометрии, методов функциональной диагностики (пульсоксиметрии, миографии, электрокардиографии, спирометрии, психофизиологического тестирования, активациометрии и д.р.) на занятиях мы используем интерактивные формы обучения.

При изучении анатомии и физиологии человека важной составляющей является обеспечение наглядности преподавания. Существует достаточное количество компьютерных технологий, позволяющих осуществлять интерактивное обучение. Это облегчает понимание сложных биологических процессов, а так же делает более доступным усвоение больших объемов нового материала путем систематизации полученных знаний. Объяснение становится более наглядным. Для каждого лекционного занятия подготовлена мультимедийная презентация, в которую включены рисунки из современных атласов нормальной анатомии. В часть презентаций добавлены трехмерные компьютерные реконструкции органов и систем организма человека. Применение компьютерной анимации частично заменяет сложно реализуемую потребность работы с биологическим материалом. С помощью трехмерного моделирования человеческого тела студенты 
могут легко ознакомиться не только со строением отдельных органов и тканей, но и с функционированием организма в целом. Общеизвестно, что лекции, подготовленные с применением компьютерных технологий, усваиваются студентами качественнее [4, 7].

В настоящее время значимые методические приемы обучения связаны с внедрением интерактивных технологий обучения. Избежать проблемы нехватки нужной узкоспециализированной литературы можно используя электронные атласы. Они устанавливаются на планшет или ноутбук, которые есть практически у всех студентов. Электронные учебники с внедренными гиперссылками позволяют мгновенно переходить к нужным разделам, увеличивать и сворачивать необходимые иллюстрации, таблицы и диаграммы. Использование интерактивных энциклопедий и атласов «Анатомия и физиология человека» позволяет дополнить информативную базу в рамках изучаемого курса и расширить методические возможности преподавателя за счёт различных составляющих (видеороликов, анимаций и т.д.).

Учебно-методические материалы по анатомии и физиологии человека разработаны с учетом вероятности отсутствия студентов на аудиторных занятиях (участие в соревнованиях и учебно-тренировочных сборах), в них подробно представлены рекомендации по изучению отдельных разделов и тем дисциплин. Даны пояснения по теоретическому материалу, вынесенному на самостоятельное изучение. Подробно описана структура выполнения и оформления лабораторных работ. Разработаны рекомендации по подготовке к экзамену.

Еще одним положительным аспектом в изучении предмета с использованием альтернативных методов являются компьютерные тесты по пройденному материалу. С их помощью студенты могут самостоятельно оценить свои знания и быстро получить результат, без помощи преподавателя. В обучении также используется кейстехнология («case-study»), с применением ситуационных задач, которые способствуют усвоению знаний и формированию умений и навыков в результате активной самостоятельной деятельности студентов по решению проблемных вопросов. Использование современных информационно-коммуникационных технологий в препо- 
давании анатомии и физиологии человека повышает эффективность восприятия студентами учебного материала.

\section{Список литературы}

1. Еланцев А.Б., Маутенбаев А.А. Особенности преподавания физиологических предметов студентам, обучающимся по специальности «Физическая культура и спорт». Казахский Национальный Университет имени Аль-Фараби. Алматы. Казахстан. URL: http://pps.kaznu. kz/2/Main/FileShow2/14323/84/3/5/0/ (дата обращения: 25.11.2019).

2. Иванов В.Б. Формирование Готовности Будущих Учителей-Предметников К Организации Физического Воспитания Учащихся Сельских Школ: Диссертация на соискание ученой степени кандидата педагогических наук. Уфа, 2000. 166 с.

3. Интерактивные образовательные технологии в преподавании анатомии / Кацук Л.Н., Каргалова Е.П., Ботвич Т.А., Момот Л.Н. // Инновационные технологии в высшем медицинском образовании. Проблемы. Анализ. Суждения. 2013. С. 98-101.

4. Литвинова В.В., Колот Н.М. Изучение анатомии человека в свете новых информационных технологий. Проблемы и перспективы // Международный журнал экспериментального образования. 2014. №10. С. 173 175. URL: https://elibrary.ru/download/elibrary_22308432_80433022. pdf (дата обращения: 20.12.2019).

5. Методологические принципы и инновационные методы преподавания дисциплины анатомия человека / Артюхина А.И., Агеева В.А., Горелик Е.В., Багрий Е.Г., Чеканин И.М., Федотова Ю.М., Орехов С.Н., Матвеев С.В. // Научное обозрение. Педагогические науки. 2016. №6. С. 31-35. URL: https://elibrary.ru/download/elibrary_28769840_98806283. pdf (дата обращения: 20.12.2019).

6. Опыт реализации ФГОС ВПО в преподавании анатомии / Жуков А.В., Байбаков С.Е., Вологина Н.И., Чигрин С.В., Север И.С., Ваньянц А.Б., Матвиенко О.Н. // Международный журнал экспериментального образования. 2014. №4-1. С. 104-106.

7. Погонышева И.А., Погонышев Д.А. Традиции и инновации в преподавании физиологии человека // Физиологические механизмы 
адаптации человека: материалы международной научно-практической конференции. Тюмень: изд-во «Лаконика», 2012. С. 8-11.

8. Резник Н.А., Черношеина Л.А. Что мы видим в учебных книгах и на обучающих $\mathrm{CD}$-дисках, изучая анатомию и физиологию тела человека? // Образовательные технологии и общество. Т.12. №3. 2009. URL: https://elibrary.ru/item.asp?id=12939842 (дата обращения: 18.11.2019).

9. Рудаскова Е.С., Зубарева Е.В. Формирование ключевых компетенций у студентов вуза физкультурного профиля в процессе преподавания анатомии человека. Физическое воспитание и спортивная тренировка. № 1 (15). 2016. C. 106-111. URL: https://elibrary.ru/download/ elibrary_25871046_47432839.pdf

10. Самойлина В.Н. Учебно-методическое обеспечение дисциплины «Анатомия человека» для студентов направления «Физическая культура» // Вестник БФУ им. И. Канта. 2014. №5. URL: https://elibrary.ru/download/ elibrary_21545617_43613717.pdf (дата обращения: 20.11.2019).

11. Самойлов В.О., Голубев В.Н. Современные компьютерные и интернеттехнологии в преподавании нормальной физиологии // Вестник Российской военно-медицинской академии. 2008. № 3 (23). С. 165-169.

\section{References}

1. Elancev A.B., Mautenbaev A.A. Osobennosti prepodavanija fiziologicheskih predmetov studentam, obuchajushhimsja po special'nosti «Fizicheskaja kul'tura $i$ sport» [Features of teaching physiological subjects to students studying in the specialty "Physical Culture and Sports"]. Almaty. Kazahstan. http://pps.kaznu.kz/2/Main/FileShow2/14323/84/3/5/0/

2. Ivanov V.B. Formirovanie gotovnosti budushchih uchitelej-predmetnikov k organizacii fizicheskogo vospitaniya uchashchihsya sel'skih shkol [The formation of readiness of future subject teachers for the organization of physical education of students in rural schools]. Ufa, 2000. $166 \mathrm{p}$.

3. Kacuk L.N., Kargalova E.P., Botvich T.A., Momot L.N. Innovacionnye tehnologii v vysshem medicinskom obrazovanii. Problemy. Analiz. Suzhdenija [Innovative technologies in higher medical education. Problems. Analysis. Judgments]. 2013. P. 98-101. 
4. Litvinova V.V., Kolot N.M. Mezhdunarodnyj zhurnal jeksperimental'nogo obrazovanija. 2014. №10. P. 173-175. https://elibrary.ru/download/ elibrary_22308432_80433022.pdf

5. Artjuhina A.I., Ageeva V.A., Gorelik E.V., Bagrij E.G., Chekanin I.M., Fedotova Ju.M., Orehov S.N., Matveev S.V. Nauchnoe obozrenie. Pedagogicheskie nauki. 2016. №6. P. 31-35. https://elibrary.ru/download/ elibrary_28769840_98806283.pdf

6. Zhukov A.V., Bajbakov S.E., Vologina N.I., Chigrin S.V., Sever I.S., Van'janc A.B., Matvienko O.N. Mezhdunarodnyj zhurnal jeksperimental'nogo obrazovanija. 2014. №4-1. P. 104-106.

7. Pogonysheva I.A., Pogonyshev D.A. Fiziologicheskie mehanizmy adaptacii cheloveka: materialy mezhdunarodnoj nauchno-prakticheskoj konferencii [Physiological mechanisms of human adaptation: materials of an international scientific and practical conference]. Tjumen': izd-vo «Lakonika», 2012. P. 8-11.

8. Reznik N.A., Chernosheina L.A. Obrazovatel'nye tehnologii i obshhestvo. V.12. №3. 2009. https://elibrary.ru/item.asp?id=12939842

9. Rudaskova E.S., Zubareva E.V. Fizicheskoe vospitanie i sportivnaja trenirovka. № 1 (15). 2016. P. 106-111. https://elibrary.ru/download/elibrary_25871046_47432839.pdf

10. Samojlina V.N. Vestnik BFU im. I. Kanta. 2014. №5. https://elibrary.ru/ download/elibrary_21545617_43613717.pdf

11. Samojlov V.O., Golubev V.N. Vestnik Rossijskoj voenno-medicinskoj akademii. 2008. № 3 (23). P. 165-169.

\section{ДАННЫЕ ОБ АВТОРАХ}

Погонышева Ирина Александровна, к.б.н., доцент ФГБОУ ВО «Ниюневартовский государственный университет» ул. Ленина, 56, г. Нижневартовск, 628605, Российская Федераџия

Скоробогатова Ольга Николаевна, к.б.н., доцент ФГБОУ ВО «Нижневартовский государственный университет» ул. Ленина, 56, г. Ниюневартовск, 628605, Российская Федераџия severina.i@bk.ru 


\section{DATA ABOUT THE AUTHORS}

\section{Pogonysheva Irina Aleksandrovna, Associate Professor}

Nizhnevartovsk State University

56, Lenin St., 56, Nizhnevartovsk, 628605, Russian Federation ORCID: 0000-0002-5759-0270

Scopus Author ID: 57194619104

\section{Skorobogatova Olga Nikolaevna, Associate Professor}

Nizhnevartovsk State University

56, Lenin St., 56, Nizhnevartovsk, 628605, Russian Federation severina.i@bk.ru

ORCID: 0000-0003-3772-8831

Scopus Author ID: 57201665280 